the disease." If this happy result is obtained it will, without doubt, be due to the work done by the Royal Society Commission, who gained their knowledge on the subject by experimentation on animals.

Cromer, President.

Sydney Holland, Chairman of Committee.

F. M. Sandwith, Hon. Treasurer.

Stephen Paget, Hon. Secretary.

2 I Ladbroke Square, London, W., November I.

\section{The Definicion of Mass.}

IN NATURE for October 26 your reviewer, in criticising "An Elementary Text-book of Physics," writes :-

"In common with so many other text-books on this subject, this book lacks the fundamental definition of 'mass.' The author introduces the term 'mass' without definition in order to define force, and then uses this definition for the purpose of defining mass. Few writers on mechanics appear to realise that a definition of mass apart from force is the essential first step from the point of view of absolute measurement."

I am not concerned to defend this particular text-book, of which I have no knowledge, but I should be grateful, in common with many of your readers, if your reviewer would give us a satisfactory definition of mass apart from force (the italics are his own). I presume he would not be content with the fatuous statement that "Mass means quantity of matter"! Apparently Sir Oliver Lodge must be included amongst those censured, for in his "Elementary Mechanics" he writes:-

"We see, then, that mass is measured, and must be held to be defined, by the property of inertness possessed by matter-that is, by its requiring force to move it if at rest, and to stop it if in motion."

The same view is expressed by Clerk Maxwell in his invaluable little book "Matter and Motion," article xlvi.

Let us be frank about this question. The idea of force, like the idea of temperature, is derived from our bodily sensations, and is therefore suspect in some quarters. It is said that our sensations are not trustworthy. Nevertheless, we can form from them by long experience fairly accurate estimations both of force and temperature. To measure temperature we generally observe the expansion of a material body. To measure force we can use the deformation produced by it when acting on some portion of matter-the statical method; or we may measure the acceleration produced in a particular body-the dynamical method. The two methods give concordant results. We observe the effects of changes of temperature; we infer the passage of " heat" from one body to another. We observe the effects of force in producing acceleration. We find that the ratio of force to acceleration (or, what is equivalent, the ratio of impulse to change of velocity) is (approximately) constant for a particular body. We infer the existence of "mass," which is simply the value of this ratio. To say that "mass" is indestructible is to affirm that this ratio remains constant through the range of our experiments. If we extend the range we are led to believe that the ratio is no longer constant when the velocity of the body approaches the velocity of light.

H. S. A.

IT gives me much pleasure to comply with "H. S. A.'s" request expressed in his letter, but, at the same time, I should like to refer him to chapter iii. of Porter's "Intermediate Mechanics" for a clear and exact statement with regard to this question.

In the first place, it should be pointed out that definitions are of two kinds, qualitative and quantitative, and it was in the latter sense that the term was used in that portion of my review which "H. S. A." quotes. To the definition due to Lodge, regarded as purely qualitative, no objection is offered; it is when quantitative definitions are required for the purpose of measurement that the difficulties arise. Surely it is obvious that it is meaningless to define unit force as that which produces unit acceleration in unit mass, and then to define unit mass as that which acquires unit acceleration under the action of unit force. Of course, if we are content to define force in terms of the deformation it produces in a given piece of material, mass may then be measured in terms of force and acceleration;

NO. 2 I94, VOL. 887 but the system of units arrived at will not be absolute. To obtain absolute units, we must be able to compare either two forces or two masses by measurements of space and time alone. The problem of defining mass quantitatively therefore resolves itself into defining the ratio of two masses in terms of space and time. This may be done as follows.

Let two masses $m_{1}$ and $m_{2}$ be isolated (a state of affairs approximately realised in Hicks's balance), and let them interact in any way. Let their accelerations at any instant be $a_{1}$ and $a_{2}$ respectively. These will be oppositely directed. Then the ratio of the masses is defined as being numerically equal to the inverse ratio of the accelerations, or

$$
m_{1} / m_{2}=-a_{2} / a_{1}
$$

the negative sign expressing the fact that the accelerations are opposed in direction. We may prove that the definition is valid by extending the experiments to a number of masses taken in pairs, and finding that tne results are consistent. The unit of mass may now be fixed, and that of force defined in terms of it. Further, it may be pointed out that as consequences of the experimental verification of the validity of the above mode of definition, the principles of the equality of action and reaction, and that of the conservation of momentum, immediately follow.

From this point of view, therefore, we regard force as being a mass-acceleration rather than mass as the ratio of force to acceleration. The thermal analogy of Dr. Allen, if extended, suits the argument excellently. We do not obtain an absolute scale of temperature until we make it independent of any particular substance; neither are we able to measure force absolutely until its scale ceases to depend upon the behaviour of any special body under its action.

The Reviewer.

\section{Altitude and Animal Development.}

Some time ago I found in the alluvium of a little Derbyshire stream a tubifioid of a species and genus new to Britain. It was characterised by its large lymph corpuscles and its Pachydrilus-like form, on which account it was named Meganympha pachydriloides, Friend. The description showed that the animal possessed an average of fortyfive segments, three or four forked setæ like Limnodrilus, a brain deeply lobed behind, spermathecæ pear-shaped or globular, and a penis-sheath, or large penial seta. While working out some species of Fridericia a few days ago, and turning to Bretscher (Revue Suisse de Zoologie, Igor) for some details, my attention was directed to his description of Rhyacodrilus falciformis, and it appeared evident that the Derbyshire worm was one with the Swiss. ${ }^{1}$ But Bretscher states that the alpine forms have only thirty segments. Issel, de Ribaucourt, and Bretscher have recently given us many facts to show that annelids of the same species are very much smaller when found high up in the Alps than when found in the valleys. The foregoing seems to be an interesting confirmation of these statements.

But I find that other factors are at work. It is many years since Vejdovsky first described the little annelid known as Achæta, on account of the absence of setæ, but it is only within the last few months that specimens have been found in England. Southern found three different species in Ireland two years ago, and I have found the same number, though differing in kind, in England. Now Vejdovsky gives $15 \mathrm{~mm}$. as the length of Achaeta bohemica; but Southern says that though the Irish specimens agree with the Bohemian in other respects, they are but $5^{-6} \mathrm{~mm}$. in length. In August I found $A$. bohemica, Vej., in Kew Gardens, and the length agreed with the Irish forms. On November 7 I took the same species from a little grass plot in the heart of the city of Nottingham, and the specimens again measure 5-6 $\mathrm{mm}$.

It seems easy to account for the difference in size in the case of Rhyacodrilus; but can any zoologist or biologist suggest an explanation of the difference between the Bohemian and British forms of Achæta?

Hilderic Friend.

I 10 Wilmot Road, Swadlincote, Burton-on-Trent.

1 Since writing the above I have discovered that Rhyacodrilus was described in 10,04 by Ditlevsen as Ilyodrilus filiformis. He was familiar with Bretscher's work, but did rot observe that the Danish tubificid had already been diagnosed. 